http://dx.doi.org/10.32929/2446-8355.2018v27n4p396-406

\title{
DESEMPENHO AGRONÔMICO DE 13 GENÓTIPOS DE GIRASSOL NO SUDOESTE BAIANO
}

Bismark Lopes Bahia ${ }^{1}$, Renan Thiago Carneiro Nunes ${ }^{1 *}$, Vandearley Neves de Souza ${ }^{2}$, Breno Rosa Neves ${ }^{1}$, Giliarde Alves Reis ${ }^{3}$, Erison Martins de Souza ${ }^{4}$, Leandro Gonçalves dos Santos $^{5}$, Evilásio dos Santos Souza ${ }^{3}$, Ana Paula Oliveira Caetano ${ }^{1}$

\footnotetext{
${ }^{1}$ Programa de Pós-Graduação em Agronomia da Universidade Estadual do Sudoeste da Bahia, Estrada do Bem Querer, Km 4, 45083-900, Vitória da Conquista, BA, Brasil. *E-mail: renanthiago_tn@ @otmail.com

${ }^{2}$ Graduando em Agronomia, Instituto Federal de Educação, Ciência e Tecnologia Baiano, Guanambi, BA.

${ }^{3}$ Mestrando em Produção Vegetal no Semiárido, Instituto Federal de Educação, Ciência e Tecnologia Baiano, Campus Guanambi, BA.

${ }^{4}$ Mestrando em Recursos Genéticos Vegetais, Universidade Federal do Recôncavo da Bahia, UFRB, Cruz das Almas, BA.

${ }^{5}$ Instituto Federal de Educação, Ciência e Tecnologia Baiano, Campus Guanambi, Guanambi, BA.
}

Recebido: 01/06/2017; Aceito: 18/09/2018

RESUMO: O cultivo de girassol (Helianthus annuus L.) se destaca por ser uma planta de ciclo curto, ter alto teor de óleo nos grãos, aonde o mesmo é utilizado para produção de biodiesel e alimentação humano, podendo também ser empregada para alimentação animal, assim como a silagem da planta e a torta proveniente da extração do óleo. Diante desses fatores, buscou-se avaliar o desempenho da cultura em diferentes condições no Sudoeste Baiano. O experimento foi realizado em condições de campo na área do Instituto Federal de Educação, Ciência e Tecnologia Baiano Campus Guanambi, avaliando-se o desempenho produtivo de 13 genótipos no semiárido baiano. O delineamento experimental foi em blocos casualizados com quatro repetições. O ciclo da cultura foi de 120 dias. Houve diferença estatística $(\mathrm{p}<0,05)$ para os caracteres produção de grãos, peso de 1000 aquênios, produção de matéria seca na floração, área foliar, altura de inserção do capítulo, diâmetro do capítulo e o rendimento de óleo, não havendo diferença apenas para os teores de $\mathrm{N}, \mathrm{P}$ e $\mathrm{K}$ no florescimento. Os genótipos CF 101, BRS G43, HÉLIO 250 e SYN 045 foram os que apresentaram simultaneamente maior rendimento de grãos e de óleo. O genótipo CF 101 se destacou por possuir baixa estatura.

Palavras-chave: Helianthus annuus. Produtividade. Melhoramento genético. Biodiesel.

\section{COMPETITIVE AGRONOMIC PERFORMANCE OF 13 SUNFLOWER GENOTYPES IN THE SOUTHWEST OF BAHIA}

\begin{abstract}
The cultivation of sunflower (Helianthus annuus L.) stands out because it is a short-cycle plant, has a high oil content in the grains, where it is used for biodiesel and human food production, and can also be used for animal feed. such as the silage of the plant and the pie from the extraction of the oil. Considering these factors, the objective was to evaluate the performance of the crop in different conditions in the Southwest of Bahia. The experiment was carried out under field conditions in the Baiano Campus Guanambi Federal Institute of
\end{abstract}


Education, Science and Technology, evaluating the productive performance of 13 genotypes in the semi-arid region of Bahia. The experimental design was in a randomized block with four replicates. The culture cycle was 120 days. There was a statistical difference $(\mathrm{p}<0.05)$ for the characteristics of grain yield, weight of 1000 achenes, dry matter production at flowering, leaf area, chapter insertion height, chapter diameter and oil yield, with no difference only for the N, P and K contents at flowering. Genotypes CF 101, BRS G43, HÉLIO 250 and SYN 045 showed the highest yields of grain and oil simultaneously. The CF 101 genotype was characterized by short stature.

Key words: Helianthus annuus. Yield. Genetical enhancement. Biodiesel.

\section{INTRODUÇÃO}

A constante busca por alternativa para a produção de biocombustível levou ao aumento em pesquisas em diversas culturas, dentre elas o girassol (Helianthus annuus L.), que é apontada por Urquiaga et al. (2005) como uma das culturas promissoras para a produção de biocombustíveis, pois, possui altas produtividades de óleo (CASTRO et al., 1996a), menor custo de produção de biocombustível (BARROS et al., 2006), boa qualidade do co-produto (torta) usada na produção de ração e ampla adaptabilidade a diferentes condições edafoclimáticas (GRUNVALD et al., 2009).

O cultivo pode ser em sistema de rotação e sucessão, estando adaptado às tecnologias de cultivos já aplicadas nos cultivos de grãos, sendo resistente a seca e ciclo curto (CAPONE et al., 2012a).

No Brasil, a safra 2015/16 teve uma área plantada de girassol aproximadamente de 111,5 mil ha ${ }^{-1}$ com uma produtividade média de $1.473 \mathrm{~kg} \mathrm{ha}^{-1}$ (CONAB, 2015). A produtividade da cultura é influenciada pela época de semeadura, genótipo, manejo adequado da fertilidade do solo e pela disponibilidade de água, podendo ser cultivada em uma ampla área no Brasil (LEITE et al., 2005).

Bezerra et al., (2014) encontraram que o ambiente modifica as características da planta, como: diâmetro do caule, comprimento da haste, número de folhas, área foliar e índice de área foliar e produtividades de aquênios. Essas informações demonstram a importância da seleção de genótipos adaptados para cada condição edafoclimática, sendo muito influenciado pela interação ambiente $\mathrm{x}$ genótipo utilizado.

Diante deste cenário, surge a necessidade de avaliar os genótipos mais adequados para cada região. O presente trabalho buscou, portanto, avaliar o desempenho produtivo de diferentes genótipos de girassol nas condições edafoclimáticas do sudoeste baiano.

\section{MATERIAL E MÉTODOS}

O experimento foi realizado na área experimental do Instituto Federal de Educação, Ciência e Tecnologia Baiano Campus Guanambi, localizado no distrito de Ceraíma, 
município de Guanambi, micro Região da Serra Geral, Sudoeste da Bahia, situado a $528 \mathrm{~m}$ de altitude, nas coordenadas $14^{\circ} 13^{\prime} \mathrm{S} ; 42^{\circ} 46^{\prime} \mathrm{W}$.

Segundo a classificação de Köppen, o clima está na transição entre Aw e BSw’h', semiárido quente e seco. De acordo com a série histórica a pluviosidade média anual é de 680 mm e a temperatura média anual é de $25,6^{\circ} \mathrm{C}$.

Os tratamentos consistiram da avaliação competitiva de 13 genótipos: M 734 (T), BRS 323, BRS G43, BRS 387, BRS G30, CF 101, ADV 5504, AGUARÁ 06, GNZ NEON, HÉLIO 250, HÉLIO 251, MG 360 E SYN 045. Estes genótipos foram provenientes da Rede Nacional de Ensaios de Girassol que é gerenciada pela Embrapa Soja.

O experimento foi instalado em delineamento de blocos completos ao acaso com quatro repetições. Cada parcela experimental foi composta por quatro linhas de $6 \mathrm{~m}$ de comprimento, com espaçamento de $0,7 \times 0,3 \mathrm{~m}$, sendo considerada como parcela útil, as duas linhas centrais, excluindo-se a primeira e a última planta de cada fileira.

Para condução do experimento a área foi submetida ao preparo convencional do solo, com aração e gradagem. As características químicas do solo $(0-20 \mathrm{~cm})$ podem ser descritas na Tabela 1.

Tabela 1. Análise química de amostra do solo da área experimental do Instituto Federal de Educação, Ciência e Tecnologia Baiano Campus Guanambi, para macronutrientes, realizada antes da instalação do experimento. Guanambi /BA, 2015. Chemical analysis of soil sample of the experimental area of the Federal Institute of Education, Science and Technology Baiano Campus Guanambi, for macronutrients, performed before the installation of the experiment. Guanambi / BA, 2015.

\begin{tabular}{|c|c|c|c|c|c|c|c|c|}
\hline pH & $\mathbf{P}$ & $\mathbf{K}^{+}$ & $\mathrm{Ca}^{2+}$ & $\mathrm{Mg}^{2+}$ & S.B. & $\mathbf{T}$ & $\mathbf{V}$ & PST \\
\hline $\mathrm{H}_{2} \mathrm{O}_{(1: 2,5)}$ & $\mathrm{mg} / \mathrm{dm}^{3}$ & \multicolumn{5}{|c|}{------------ cmol dm³ de solo ----------- } & \multicolumn{2}{|c|}{------\% ------ } \\
\hline 7,3 & 135 & 0,82 & 3,7 & 1,7 & 4,8 & 6,3 & 85 & 1 \\
\hline
\end{tabular}

Para $\mathrm{P}$ e K, foi utilizado Extrator Mehlich; para $\mathrm{Ca}, \mathrm{Mg}$ e, foi utilizado $(\mathrm{KCl} 1 \mathrm{~N})$. For $\mathrm{P}$ and $\mathrm{K}$, Mehlich Puller was used; for $\mathrm{Ca}, \mathrm{Mg}$ and, $(1 \mathrm{~N} \mathrm{KCl})$ was used.

A cultura foi manejada com irrigação complementar por gotejamento. Na ocasião da semeadura foi realizada uma adubação com $40 \mathrm{~kg} \mathrm{ha}^{-1}$ de Nitrogênio (Ureia), $80 \mathrm{~kg} \mathrm{ha}^{-1} \mathrm{de}$ Fósforo (Super Fosfato Simples) e $40 \mathrm{~kg} \mathrm{ha}^{-1}$ de Potássio (Cloreto de Potássio), com base na recomendação de (CASTRO et al., 1996b). Aos vinte e cinco dias após a emergência das plantas, realizou-se a adubação de cobertura com $40 \mathrm{~kg} \mathrm{ha}^{-1}$ de Nitrogênio (Ureia), $40 \mathrm{~kg} \mathrm{ha}^{-1}$ de Potássio (Cloreto de Potássio) e $2 \mathrm{~kg} \mathrm{ha}^{-1}$ de boro (Ácido Bórico) de acordo com o manual recomendações para uso de corretivos e fertilizantes em Minas Gerais ( $5^{\mathrm{a}}$ aproximação) (CHAGAS et al., 1999), ao mesmo tempo em que também foi feita a capina.

O estado nutricional do girassol foi realizado mediante a coleta das amostras de tecido foliar, no florescimento pleno, que ocorreu quando $50 \%$ das plantas estavam com flores abertas. Coletou-se as folhas do terço médio de quatro plantas por parcela (MALAVOLTA et al., 1997). Estas foram lavadas com água destilada para retirada de impurezas e secadas em estufa com circulação forçada de ar a $65^{\circ} \mathrm{C}$ até obtenção de massa constante. Após secagem as folhas foram trituradas em moinho de facas tipo Wiley. Determinou-se, o teor do 
nitrogênio (N) através da digestão sulfúrica (TEMMINGHOFF e HOUBA, 2004) e quantificou-se, pela destilação de Kjeldahl (MIYAZAWA et al., 1999). Os teores de fósforo (P) e potássio (K) seguiu-se a metodologia descrita por (MIYAZAWA et al., 1999), com obtenção do extrato pela digestão nitroperclórica. O P foi determinado por colorimetria do azul de molibdênio e o $\mathrm{K}$ por fotometria de chama.

No florescimento pleno também se avaliou o aporte de massa seca total da parte aérea pelo método destrutivo, altura da inserção do capítulo e área foliar. Para a obtenção da massa seca foram coletadas duas plantas na parcela útil, secas em estufa com circulação forçada de ar a $65{ }^{\circ} \mathrm{C}$ até obtenção de massa constante, procedendo-se a pesagem para obtenção da matéria seca. A altura da inserção do capítulo foi mensurada com auxílio de fita métrica, desde o solo até a base do capítulo de todas as plantas da área útil. Os capítulos da área útil foram cobertos com sacos de pano com o objetivo de evitar o ataque de pássaros e não comprometer a avaliação da produtividade.

A área foliar foi determinada conforme descrito por Aquino et al., (2011) que consiste em medir o comprimento e a largura de todas as folhas das plantas e aplicar a Eq.:

$$
Y=0,5405 X^{1,0212}
$$

onde: $\mathrm{X}$ é o produto do comprimento e largura da folha, sendo que a área foliar é o somatório de todos os valores de $\mathrm{Y}$ encontrados para as folhas da planta.

Procedeu-se a colheita quando os aquênios apresentaram um teor aproximado de $11 \%$ de umidade. Mediu-se o diâmetro dos capítulos colhidos com auxílio de fita métrica, sendo posteriormente desgranados manualmente. O peso de 1000 aquênios foi obtido pela contagem e pesagem em balança analítica. Obteve-se o teor de óleo pela prensagem dos aquênios, préaquecidos a $65^{\circ} \mathrm{C}$ por $1 \mathrm{~h}$, em prensa hidráulica manual sob uma pressão de $495 \mathrm{kgf} \mathrm{cm}^{-2}$ por 15 min e posteriormente convertido para rendimento de óleo (adaptado de CARVALHO, (2011) e Pighinelli et al., (2009).

Os obtidos foram submetidos à análise de variância pelo teste de $\mathrm{F}$ ao nível de $0,05 \mathrm{e}$ 0,01 de probabilidade utilizando o programa estatístico Sisvar (FERREIRA, 2011) e havendo significância procedeu-se o teste de médias de Skott-Knott.

\section{RESULTADOS E DISCUSSÃO}

O resumo da análise de variância (Tabela 1) demonstrou efeito significativo entre os genótipos ao nível de 0,05 de probabilidade para as seguintes características: altura de planta (AP), diâmetro do capítulo (DC), massa seca (MS), área foliar (AF), produtividade (PR).

As variáveis peso de mil aquênios (PM) e rendimento de óleo (RO) também demonstraram efeito significativo a 0,05 de probabilidade, contudo, não foram obtidas diferenças significativas para os teores foliares de N, P e K entre os genótipos conforme mostra o resumo da análise de variância (Tabela 2).

Analisando a AP verificou-se que os valores formam quatro grupos que diferiram entre si (Tabela 3), os genótipos CF 101 e MG 360 apresentaram valores médios inferiores aos 
demais, sendo o BRS G30 o que apresentou a maior altura. Os genótipos menores possuem menor possibilidade de ocorrer à quebra do capítulo e o acamamento.

Tabela 2. Resumo da análise de variância, das características altura da planta (AP), diâmetro do capítulo (DC), massa seca (MS), área foliar (AF) e produtividade (PR) de 13 genótipos de girassol. Summary of analysis of variance, plant height (AP), leaf diameter (DC), dry matter $(D M)$, leaf area $(F A)$ and yield $(P R)$ of 13 sunflower genotypes.

\begin{tabular}{|c|c|c|c|c|c|c|}
\hline \multirow{2}{*}{ F.V } & \multirow{2}{*}{ GL } & \multicolumn{5}{|c|}{ Quadrado Médio } \\
\hline & & AP & DC & MS & $\mathrm{AF}$ & PR \\
\hline GENOTIPO & 12 & $1933,98^{* *}$ & $3,07^{* *}$ & $80837463,08^{* *}$ & $7866358,04^{* *}$ & $873758,10^{* *}$ \\
\hline BLOCO & 3 & $216,93^{\mathrm{ns}}$ & $2,37^{\mathrm{ns}}$ & $5511166,60^{\mathrm{ns}}$ & $1466386,96^{\mathrm{ns}}$ & $2440600,12^{*}$ \\
\hline ERRO & 36 & 186,76 & 1,07 & 8641225,77 & 705231,26 & 835469,87 \\
\hline $\mathrm{CV}(\%)$ & & 7,37 & 5,59 & 23,47 & 12,27 & 18,74 \\
\hline
\end{tabular}

Tabela 3. Resumo da análise de variância, das características peso de mil aquênios (PM), rendimento de óleo $(\mathrm{RO})$, teor de potássio foliar $(\mathrm{K})$, teor de fósforo foliar $(\mathrm{P})$ e teor de nitrogênio foliar (N) em 13 genótipos de girassol. Summary of analysis of variance, characteristics of thousand achenes (PM), oil yield (RO), foliar potassium content $(K)$, foliar phosphorus content $(P)$ and foliar nitrogen $(N)$ content in 13 sunflower genotypes.

\begin{tabular}{ccccccc}
\hline \multirow{2}{*}{ F.V } & \multirow{2}{*}{ GL } & \multicolumn{5}{c}{ Quadrado Médio } \\
\cline { 3 - 7 } & & PM & RO & K & P & N \\
\hline GENÓTIPO & 12 & $3626,04^{* *}$ & $61,62^{* *}$ & $113,12^{\text {ns }}$ & $36,85^{\text {ns }}$ & $37,94^{\text {ns }}$ \\
BLOCO & 3 & $420,18^{\text {ns }}$ & $0,62^{\text {ns }}$ & $133,02^{\text {ns }}$ & $9,50^{\text {ns }}$ & $16,66^{*}$ \\
ERRO & 36 & 80,98 & 2,74 & 56,02 & 18,89 & 54,23 \\
\hline CV $(\%)$ & & 8,88 & 23,30 & 15,55 & 15,82 & 18,94 \\
\hline
\end{tabular}

${ }^{\mathrm{ns}}=$ não significativo; $* \mathrm{e}^{* *}$, significativo a 0,05 e 0,01 de probabilidade pelo teste $\mathrm{F}$, respectivamente. ${ }^{n s}=n o t$ significant; $*$ and $* *$, significant at 0.05 and 0.01 probability by the $F$ test, respectively.

Aquino et al. (2013) avaliando diversas cultivares em regime irrigado em Januária-MG encontraram nas cultivares M734, HÉLIO 250 e HÉLIO 251 alturas de plantas superiores as encontradas no experimento em questão, estes resultados devem-se, provavelmente, ao maior espaçamento utilizado no seu trabalho. Nobre et al. (2012) trabalhando com diferentes locais de cultivo, encontraram valores de AP inferiores na época de safrinha em Nova PorteirinhaMG para as cultivares BRS G30 e M734 e superiores para os genótipos CF 101 e M734 em Jaíba-MG, comportamento esse que pode ser atribuído às diferentes condições edafoclimáticas.

O maior diâmetro de capítulo $(19,73 \mathrm{~cm})$ foi observado no genótipo AGUARÁ 06, contudo este não diferenciou dos genótipos ADV 5504, BRS 387, BRS G30, GNZ NEON e HÉLIO 251. Capítulos de tamanho maior estão associados a uma maior quantidade de grãos, o que pode refletir em maior produtividade. O diâmetro de capitulo observado no genótipo HÉLIO 251 foi superior aos observados por Capone et al. (2012b), em estudo com girassol semeado em diferentes épocas, contudo, foram inferiores aos valores obtidos por (NOBRE et al., 2012), cultivando girassol em diferentes localidades. 
O desenvolvimento expressivo dos capítulos no presente estudo pode estar associado ao controle da irrigação, aonde proporcionou um melhor desenvolvimento vegetativo, melhorando assim, o crescimento dos capítulos e das demais variáveis com exceção do teor de óleo.

A maior produção de MS (20,12 $\left.\mathrm{Mg} \mathrm{ha}^{-1}\right)$ foi observada no genótipo BRS G30, contudo, este não diferiu pelo teste de médias dos genótipos BRS 323 (T), BRS 387, CF 101, GNZ NEON e HÉLIO 251. De modo geral, os valores observados foram superiores aos encontrados por Tomich et al. (2003), com exceção do genótipo ADV 5504 que foi inferior a todos testado no experimento citado. Santos et al. (2015), trabalhando com diferentes doses de fósforo e boro no hibrido HÉLIO 358, obtiveram MS máxima de 8,42 $\mathrm{Mg} \mathrm{ha}^{-1}$, valor este que foi superior ao genótipo ADV 5504, porém, inferior aos demais genótipos avaliados.

Tabela 4. Altura de planta (AP), diâmetro de capítulo (DC), massa seca da parte aérea (MS) e área foliar (AF) em 13 genótipos de girassol. Plant height (AP), shoot diameter (DC), dry shoot mass (DM) and leaf area (FA) in 13 sunflower genotypes.

\begin{tabular}{ccccc}
\hline Material & AP $(\mathrm{cm})$ & DC $(\mathrm{cm})$ & MS $\left(\mathrm{Mg} \mathrm{ha}^{-1}\right)$ & AF $\left(\mathrm{cm}^{2}\right)$ \\
\hline ADV 5504 & $181,53 \mathrm{c}$ & $19,25 \mathrm{a}$ & $3,55 \mathrm{c}$ & $4356,79 \mathrm{c}$ \\
AGUARÁ 06 & $212,99 \mathrm{~b}$ & $19,73 \mathrm{a}$ & $10,12 \mathrm{~b}$ & $8420,84 \mathrm{a}$ \\
BRS 323 (T) & $193,68 \mathrm{c}$ & $17,69 \mathrm{~b}$ & $15,78 \mathrm{a}$ & $7856,63 \mathrm{a}$ \\
BRS 387 & $175,84 \mathrm{c}$ & $18,79 \mathrm{a}$ & $13,31 \mathrm{a}$ & $6529,94 \mathrm{~b}$ \\
BRS G30 & $235,26 \mathrm{a}$ & $19,53 \mathrm{a}$ & $20,12 \mathrm{a}$ & $8709,66 \mathrm{a}$ \\
BRS G43 & $177,67 \mathrm{c}$ & $17,85 \mathrm{~b}$ & $9,59 \mathrm{~b}$ & $5433,01 \mathrm{c}$ \\
CF 101 & $154,67 \mathrm{~d}$ & $17,18 \mathrm{~b}$ & $16,00 \mathrm{a}$ & $6169,75 \mathrm{~b}$ \\
GNZ NEON & $191,94 \mathrm{c}$ & $19,32 \mathrm{a}$ & $17,07 \mathrm{a}$ & $9135,23 \mathrm{a}$ \\
HÉLIO 250 & $186,16 \mathrm{c}$ & $18,12 \mathrm{~b}$ & $11,90 \mathrm{~b}$ & $7128,56 \mathrm{~b}$ \\
HELIO 251 & $188,91 \mathrm{c}$ & $18,77 \mathrm{a}$ & $16,52 \mathrm{a}$ & $6740,96 \mathrm{~b}$ \\
M 734 (T) & $185,35 \mathrm{c}$ & $18,14 \mathrm{~b}$ & $8,89 \mathrm{~b}$ & $6987,70 \mathrm{~b}$ \\
MG 360 & $150,39 \mathrm{~d}$ & $17,04 \mathrm{~b}$ & $12,22 \mathrm{~b}$ & $6023,58 \mathrm{~b}$ \\
SYN 045 & $175,70 \mathrm{c}$ & $18,21 \mathrm{~b}$ & $8,70 \mathrm{~b}$ & $5487,11 \mathrm{c}$ \\
\hline Média & 185,39 & 18,43 & 12,52 & 6844,60 \\
\hline
\end{tabular}

Letras diferentes na coluna demonstram diferença significativa pelo teste de Skott-Knott a 0,05 de probabilidade. Different letters in the column show significant difference by the Skott-Knott test at 0.05 probability

Lobo et al. (2013), trabalhando com o genótipo HÉLIO 251 submetido a diferentes doses de lodo de esgoto para suprir as necessidades de $\mathrm{N}$, obtiveram produções de MS superior ao genótipo ADV 5504 em quase todas as doses, sendo a MS de todos os tratamentos inferiores aos demais genótipos aqui avaliados. Essa maior produção supostamente está relacionada às condições de cultivo dos diferentes trabalhos e ao melhoramento genético envolvido.

Ao avaliar a AF, observou-se que os maiores resultados foram obtidos nos genótipos AGUARÁ 06, BRS 323(T), BRS G30 e GNZ NEON, que não diferenciaram entre si e o menor valor foi verificado nos genótipos BRS G43 e ADV 5504. Os valores de AF do 
presente experimento foram superiores a AF ótima $\left(4512,6 \mathrm{~cm}^{2}\right)$ indicada por Santos et al., (2015), também avaliando diferentes genótipos de girassol, exceto para o genótipo ADV 5504 que obteve valores inferiores.

Os valores de AF auferidos no presente estudo também foram superiores aos encontrados por Neto et al. (2014). A área foliar é um parâmetro de grande importância para avaliar a competição com outras espécies, e de maneira indireta estimar a produtividade, já que se trata da medida do principal órgão fotossintetizante da planta e responsável pela produção de assimilados (MONTEIRO et al., 2005).

O genótipo mais produtivo $\left(6,90 \mathrm{~kg} \mathrm{ha}^{-1}\right)$ foi o HÉLIO 250, contudo, este não diferiu pelo teste de médias dos genótipos SYN 045, BRS 323 (T), BRS G43, BRS G30 e CF 101 (Tabela 4). A produtividade encontrada em todos os genótipos foi superior à média nacional que é de $1476 \mathrm{~kg} \mathrm{ha}^{-1}$ (COMPANHIA NACIONAL DE ABASTECIMENTO - CONAB, 2016). Os valores médios foram também superiores aos encontrados por Nobre et al. (2012); Silva et al. (2009); Capone et al. (2012b); Porto et al. (2008), que também trabalharam com alguns destes genótipos, sendo a possível causa para diferença nos resultados, o suprimento da necessidade hídrica da cultura e as condições edafoclimáticas.

Tabela 5. Produtividade (PR), peso de mil aquênios (PM) e rendimento de óleo (RO) em 13 genótipos de girassol. Productivity (PR), weight of thousand achenes (PM) and yield of oil (RO) in 13 sunflower genotypes.

\begin{tabular}{cccc}
\hline Material & PR $\left(\mathrm{Kg} \mathrm{ha}^{-1}\right)$ & PM $(\mathrm{g})$ & RO $(\%)$ \\
\hline ADV 5504 & $2,94 \mathrm{c}$ & $61,16 \mathrm{~d}$ & $18,10 \mathrm{c}$ \\
AGUARA 06 & $5,11 \mathrm{~b}$ & $87,18 \mathrm{c}$ & $22,74 \mathrm{~b}$ \\
BRS 323 (T) & $5,59 \mathrm{a}$ & $134,70 \mathrm{a}$ & $21,04 \mathrm{~b}$ \\
BRS 387 & $2,79 \mathrm{c}$ & $63,24 \mathrm{~d}$ & $15,21 \mathrm{~d}$ \\
BRS G30 & $5,76 \mathrm{a}$ & $115,27 \mathrm{a}$ & $20,55 \mathrm{~b}$ \\
BRS G43 & $6,27 \mathrm{a}$ & $134,23 \mathrm{a}$ & $23,87 \mathrm{a}$ \\
CF 101 & $6,40 \mathrm{a}$ & $106,50 \mathrm{~b}$ & $25,08 \mathrm{a}$ \\
GNZ NEON & $2,23 \mathrm{c}$ & $49,87 \mathrm{~d}$ & $14,38 \mathrm{~d}$ \\
HELIO 250 & $6,90 \mathrm{a}$ & $120,85 \mathrm{~b}$ & $25,60 \mathrm{a}$ \\
HELIO 251 & $4,30 \mathrm{~b}$ & $76,39 \mathrm{c}$ & $17,86 \mathrm{c}$ \\
M 734 (T) & $4,39 \mathrm{~b}$ & $133,26 \mathrm{a}$ & $17,77 \mathrm{c}$ \\
MG 360 & $4,94 \mathrm{~b}$ & $114,64 \mathrm{~b}$ & $25,51 \mathrm{a}$ \\
SYN 045 & $5,64 \mathrm{a}$ & $119,99 \mathrm{~b}$ & $24,01 \mathrm{a}$ \\
Média & 4,87 & 101,33 & 20,91 \\
\hline
\end{tabular}

Letras diferentes na coluna demonstram diferença significativa pelo teste de Skott-Knott a 0,05 de probabilidade. Different letters in the column show significant difference by the Skott-Knott test at 0.05 probability.

Analisando o peso de mil aquênios os maiores valores foram encontrados no BRS 323 (T), BRS G43, BRS G30 e M 734 (T), os menores foram ADV 5504, BRS 387 e GNZ NEON (Tabela 4). A média do peso de mil aquênios foi superior a encontrada por Aquino et al. (2013) trabalhando com análise de crescimento e caracteres agronômicos de diferentes genótipos. Capone et al. (2012b) avaliando diferentes épocas de semeadura no sul do 
Tocantins encontraram valores menores de PM e de DC, associando isso a possibilidade de capítulos maiores ter mais tempo para o enchimento de grãos.

Essa associação do tamanho de capítulo não foi encontrada, pois os genótipos de capítulos maiores ADV 5504 e GNZ NEON tiveram P1000 inferiores a BRS 323 (T) e BRS G43, não sendo um fator determinante para a produtividade, o que corrobora com Lopes et al. (2009). Segundo este pesquisador, a boa nutrição, o suprimento hídrico e a alta incidência luminosa são os fatores provavelmente responsáveis por obtenção de maior peso de mil aquênios.

Os teores de óleo encontrados foram muito abaixo do encontrado por Pivetta et al., (2012) e Souza et al. (2015), contudo, ressalta-se que estes autores utilizaram uma prensa contínua que é mais eficiente na extração de óleo do que as prensas descontínuas, como foi relatado por Carvalho (2011). Outro fator determinante no rendimento de óleo é o teor de umidade nos grãos, que pode ter influenciado negativamente a avaliação, já que esse teor no presente experimento foi maior que o recomendado por Pighinelli et al. (2009), que é entre $8 \mathrm{e}$ $8,5 \%$.

\section{CONCLUSÃO}

Os genótipos mais produtivos foram HÉLIO 250, SYN 045, BRS 323 (T), BRS G43, BRS G30 e CF 101.

O genótipo CF 101 apresentou menor altura o que pode facilitar a colheita mecanizada e reduzir o risco de quebra e acamamento.

Todos os genótipos possuem elevado potencial de produção de massa seca podendo ser testados para a produção de silagem.

Os genótipos CF 101, BRS G43, HÉLIO 250 e SYN 045 foram os que apresentaram simultaneamente maior rendimento de grãos e de óleo.

\section{REFERÊNCIAS BIBLIOGRÁFICAS}

AQUINO, L. A.; SILVA, F. D. B.; BERGER, P. G. Características agronômicas e o estado nutricional de cultivares de girassol irrigado. Revista Brasileira de Engenharia Agrícola e Ambiental, Campina Grande, v. 17, n. 5, p.551-557, 2013.

AQUINO, L. A.; SANTO JUNIOR, V. C.; GUERRA, J. V. S; COSTA, M. M. Estimativa de área foliar do girassol por método não destrutivo. Bragantia, Campinas, v. 70, n. 4, p.832836, 2011.

BARROS, G. S. C.; SILVA, A. P.; PONCHIO, L. A.; ALVES, L. R. A.; OSAKI, M.; CENAMO, M. Custos de produção de biodiesel no Brasil. Política Agrícola, Brasília, v. 15, n. 3, p.36-50. 2006.

BEZERRA, F. T. C.; DUTRA, A. S.; BEZERRA, M. A. F.; FILHO, A. F. O.; BARROS, G. L. Comportamento vegetativo e produtividade de girassol em função do arranjo espacial das plantas. Revista Ciência Agronômica, Fortaleza, v. 45, n. 2, p.335-343, 2014. 
CAPONE, A.; BARROS, H. B.; SANTOS, E. R.; CASTRO, E. F.; SANTOS, A. F.; FIDELIS, R. R. Efeito de épocas de semeadura de girassol na safrinha, em sucessão à soja no Cerrado Tocantinense. Revista Ceres, Viçosa, v. 59, n. 1, p.102-109, 2012.

CAPONE, A.; SANTOS, E. R.; FERRAZ, E. C; SANTOS, A. F.; OLIVEIRA, J. L.; BARROS, H. B. Desempenho agronômico de cultivares de girassol no sul do Estado Tocantins. Journal of Biotechnology and Biodiversity, Tocantinópolis, v. 3, n. 3, p.13-23. 2012.

CARVALHO, C. O. Comparação entre métodos de extração do óleo de Mauritia flexuosa L. f. (Arecaceae- buriti) para o uso sustentável na reserva de desenvolvimento Tupé: rendimento e atividade antimicrobiana. 2011. 109 f. Dissertação (Mestrado em Biotecnologia e Recursos Naturais) - Universidade do Estado do Amazonas, Manaus, 2011.

CASTRO, C.; CASTIGLIONI, V. B. R.; BALLA, A.; LEITE, P. M. V. B. C.; KAIRAM. D.; MELlO, H. C.; GUEDES. L. C. A.; FARIAS. J. R. B. A cultura do girassol. Londrina, EMBRAPA-CNPSo, 1996.

CAStro, C.; CASTIGLlONI, V. B. R.; BAlla, A. A cultura do girassol: tecnologia de produção. 2. ed. Londrina: EMBRAPA-CNPSo, 1996. 38 p.

CHAGAS, J. M.; BRAGA, J. M.; VIEIRA, C.; SALGADO, L. T.; JUNQUEIRA NETO, A.; ARAÚJO, G. A. A.; ANDRADE, M. J. B.; LANA, R. M. Q.; RIBEIRO, A. C. Feijão. In: RIBEIRO, A. C.; GUIMARÃES, P. T. G.; Alvarez, V. H. Recomendações para o uso de corretivos e fertilizantes em Minas Gerais: $5^{\text {a }}$ aproximação. Viçosa, MG: CFSEMG. p. 306309, 1999.

COMPANHIA NACIONAL DE ABASTECIMENTO - CONAB. Acompanhamento de Safra Brasileira - Grãos. Monitoramento Agrícola. SAFRA 2014/15, Brasília, v. 2, n. 10, p.1-155, 2015. Disponível em: <https://www.conab.gov.br/info-agro/safras/graos/boletim-dasafra-de-graos?start=40>. Acesso em: 09 nov. 2018.

FERREIRA, D. F. Sisvar: a computer statistical analysis system. Ciência e Agrotecnologia, Lavras, v. 35, n. 6, p.1039-1042, 2011.

GRUnVAlD, A. K.; CARVAlhO, C. G. P.; OliveIRA, A. C. B.; ANDRADE, C. A. B. Adaptabilidade e estabilidade de genótipos de girassol nos estados do Rio Grande do Sul e Paraná. Ciência e Agrotecnologia, Lavras, v. 33, n. 5, p.1195-1204, 2009.

LEITE, R. M. V. B. C.; BRIGHENTI, A. M.; CASTRO, C. Girassol no Brasil. Londrina: Embrapa Soja, 2005. 609 p.

LOBO, T. F.; FILHO, H. G.; BULL, L. T.; KUMMER, A. C. B. Efeito do lodo de esgoto e do nitrogênio nos fatores produtivos do girassol. Revista Brasileira de Engenharia Agrícola e Ambiental, Campina Grande, v. 17, n. 5, p.504-509, 2013.

LOPES, P. V. L.; MARTINS, M. C.; TAMAI, M. A.; CARVALHO, C. G. P.; OLIVEIRA, A. C. B.; TAVARES, J. A. Competição de híbridos e variedades de girassol comerciais em safrinha no oeste da Bahia. In: REUNIÃO NACIONAL DE PESQUISA DO GIRASSOL, 18, Pelotas, 2009. Anais... Pelotas: Embrapa Clima Temperado, 2009. Disponível em: 
<https://ainfo.cnptia.embrapa.br/digital/bitstream/item/34742/1/29888.pdf>. Acesso em: 09 nov. 2018.

MALAVOLTA, E.; VITTI, G. C.; OLIVEIRA, S. A. Avaliação do estado nutricional das plantas: Princípios e aplicações. 2. ed. Piracicaba: Potafos, 1997. 319 p.

MIYAZAWA, M.; PAVAN, M. A.; MURAOKA, T.; CARMO, C. A. F. S.; MELLO, W. J. Análises químicas de tecido vegetal. In: SILVA, F. C. (Ed.) Manual de análises químicas de solos, plantas e fertilizantes. Brasília: Embrapa Comunicação para Transferência de Tecnologia, 1999. p. 173-223.

MONTEIRO, J. E. B. A.; SENTELHA, P. C.; CHIAVEGATO, E. J.; GUISELINI, C.; SANTIAGO, A. V.; PRELA, A. Estimação da área foliar do algodoeiro por meio de dimensões e massa das folhas. Bragantia, Campinas, v. 64, n. 1, p.15-24, 2005.

NETO, M. E.; FRAGA, V. S.; DIAS, B. O.; SOUTO, J. S. Efeito de doses de boro no crescimento vegetativo de girassol em diferentes classes de solos. Revista Ceres, Viçosa, MG, v. 61, n. 3, p.399-405, 2014.

NOBRE, D. A. C.; RESENDE, J. C. F.; JUNIOR, D. S. B.; COSTA, C. A.; MORAIS, D. L. B. Desempenho agronômico de genótipos de girassol no norte de Minas Gerais. Revista Agro@mbiente, Boa Vista, v. 6, n. 2, p.140-147, 2012.

PIGHINELli, A. L. M. T.; PARK, K. J.; RAUEN, A. M.; OLIVEIRA, R. A. Otimização da prensagem de grãos de girassol e sua caracterização. Revista Brasileira de Engenharia Agrícola e Ambiental, Campina Grande, v. 13, n. 1, p.63-67, 2009.

PIVETTA, L. G.; GUIMARÃES, V. F.; FIOREZE, S. L.; PIVETTA, L. A.; CASTOLDI, G. Avaliação de híbridos de girassol e relação entre parâmetros produtivos e qualitativos. Revista Ciência Agronômica, Fortaleza, v. 43, n. 3, p.561-568, 2012.

PORTO, W. S.; CARVALHO, C. G. P.; PINTO, R. J. B.; OLIVEIRA, M. F.; OLIVEIRA, A. C. B. de. Evaluation of sunflower cultivars for central Brazil. Scientia Agricola, Piracicaba, v. 65 , n. 2, p.139-144, 2008.

SANTOS, L. G.; SOUZA, U. O.; CARVAlHO, Z. S.; PRIMO, D. C.; SANTOS, A. R. Análise de crescimento do girassol em função do suprimento de fósforo e boro. Bioscience Journal, Uberlândia, v. 31, n. 2, p.370-381, 2015.

SILVA, A. G.; PIRES, R.; MORÃES, E. B.; OlIVEIRA, A. C. B.; CARVAlHO, C. G. P. Desempenho de híbridos de girassol em espaçamentos reduzidos. Semina: Ciências Agrárias, Londrina, v. 30, n. 1, p.31-38, 2009.

SOUZA, F. R.; SILVA, I. M.; PELlin, D. M. P.; BERGAMIN, A. C.; SILVA, R. P. Características agronômicas do cultivo de girassol consorciado com Brachiaria ruziziensis. Revista Ciência Agronômica, Fortaleza, v. 46, n. 1, p.110-116, 2015.

TEMMINGHOFF, E. E. J. M; HOUBA, V. J. C. Plant analysis procedures. 2. ed. Dordrecht: Kluwer Academic Publishers, 2004. 179 p.

TOMICH, T. R.; RODRIGUES, J. A. S.; GONÇALVES, L. C.; TOMICH, R. G. P.; CARVALHO, A. U. Potencial forrageiro de cultivares de girassol produzidos na safrinha para 
ensilagem. Arquivo Brasileiro de Medicina Veterinária e Zootecnia, Belo Horizonte, v. 55, n. 6, p.756-762, 2003.

URQUIAGA, S.; ALVES, B. J.; BODDEY, R. M. Produção de biocombustíveis: a questão do balanço energético. Política Agrícola, Brasília, v. 14, n. 1, p.42-46, 2005. 